\title{
Consideraçóes Sobre a Apreciaçáo dos Manuscritos da Área de Educação Especial Submetidos à Revista Paidéia
}

Considerations on the AsSESSMENT OF MANUSCRIPTS AREA SPECIAL EDUCATION Submitted to Journal PAidéta

\author{
Eucia Beatriz Lopes PETEAN ${ }^{1}$ \\ Manoel Antônio dos SANTOS²
}

\section{Revista Paidéia e seu contexto}

Em 1991, com o objetivo inicial de servir como instrumento de divulgação e discussão de trabalhos científicos, foi criada a revista Paidéia, no âmbito da Faculdade de Filosofia, Ciências e Letras de Ribeirão Preto da Universidade de São Paulo (FFCLRP-USP), graças aos esforços de docentes do então Departamento de Psicologia e Educação (PAIDÉIA, 1991). A revista nasceu como Paidéia: Cadernos de Psicologia e Educação e, mais tarde, teve o nome abreviado para Paidéia.

Inicialmente, tinha periodicidade semestral e, a partir de 2002, tornou-se uma publicação quadrimestral do Programa de Pós-graduação em Psicologia da FFCLRP-USP. A revista publica trabalhos originais relacionados à Psicologia, Educação e áreas afins, que se enquadrem nas seguintes categorias: relato de pesquisa, estudo teórico (a convite) e revisão sistemática da literatura.

O Corpo Editorial é formado pelo Editor Responsável, pela Comissão Editorial composta por nove membros (Editores Associados) e pelo Conselho Editorial, composto por 25 pesquisadores de reconhecida envergadura científica, sendo quatro de Universidades de Portugal, dois do Canadá, um do Reino Unido, um da Colômbia, um dos Estados Unidos e os demais de Universidades brasileiras de diversos estados.

Em 2007, a Paidéia foi indexada no Scientific Eletronic Library Online (SciELO), biblioteca eletrônica virtual que abrange uma coleçâo selecionada de periódicos científicos brasileiros (PAIDÉIA, 2007) e, em 2012, foi indexada na base Scopus (Elsevier). A revista está incorporada em 13 indexadores, sendo dois nacionais e 10 internacionais, a saber: PsycINFO - Psychological Abstracts (American Psychological Association), PASCAL - L'Institut de l'Information Scientifique et Technique (INIST), LILACS - Literatura Latino-Americana e do Caribe em Ciências da Saúde (Centro Latino-americano y de Caribe de Informaciones em Ciências de la Salud), CLASE - Citas Latinoamericanas en Ciências Sociales y Humanidades (Universidad Nacional Autónoma de México), PSICODOC (Colégio Oficial de Psicólogos de

\footnotetext{
${ }^{1}$ Docente do Programa de Pós-graduação em Psicologia da Faculdade de Filosofia, Ciências e Letras de Ribeirão Preto da Universidade de São Paulo. Editora Associada da revista Paidéia (Ribeirão Preto) - ebpetean@ffclrp.usp.br.

${ }^{2}$ Docente do Programa de Pós-graduação em Psicologia da Faculdade de Filosofia, Ciências e Letras de Ribeirão Preto da Universidade de São Paulo. Editor Responsável da revista Paidéia (Ribeirāo Preto) - masantos@ffclrp.usp.br
} 
Madrid / Universidad Complutense de Madrid), DOAJ - Directory of Open Access Journals, Ulrich's International Periodicals Directory, Catálogo Latindex, IRESIE (Universidad Nacional Autónoma de México), Redalyc (Red de Revistas Cientificas de América Latina y el Caribe, España y Portugal) e Index-Psi Periódicos (CFP/PUCCAMP).

O processo editorial da Paidéia se pauta pela revisão às cegas (double blind review) realizada por pares, ou seja, as identidades dos autores e dos consultores ad hoc são mantidas incógnitas. A tramitação editorial inicia-se com a submissão do manuscrito à revista, que é analisado, preliminarmente, pela Comissão Editorial, de acordo com os seguintes critérios: (a) conteúdo, no que se refere à linha temática da revista; (b) originalidade, relevância do tema e qualidade da metodologia científica utilizada; (c) adequação às normas editoriais adotadas pelo periódico. Uma vez atendidos esses critérios, o manuscrito é enviado aos pareceristas que, após análise acurada, podem sugerir a recusa ou recomendar sua publicação - que pode ser condicionada à realização de alteraçóes solicitadas.

Ao longo destes 22 anos, a revista vem se aprimorando e buscando aperfeiçoar a qualidade de suas publicaçóes, tornando-se um importante e respeitado veículo de divulgação científica, principalmente na área da Psicologia e Educação. Está classificada no qualis CAPES Periódicos, área da Psicologia, como A1, e na Educação como B1. O acervo completo da revista encontra-se digitalizado e disponibilizado on-line, em livre acesso, na biblioteca SciELO: http:// www.scielo.br/scielo. Ao se lançar em busca da internacionalização, a partir de 2012, os artigos encontram-se disponíveis na íntegra em língua inglesa, como parte dos esforços da revista de aumentar a visibilidade dos conteúdos publicados.

\section{A Educaçáo Especial na revista Paidéia}

Visando a conhecer qual tem sido o papel da Paidéia na divulgação de conhecimento, especificamente na área de Educação Especial, publicado nos últimos cinco anos (2007 a 2011), realizamos um levantamento nos arquivos da revista. Desse modo, buscamos traçar um perfil da revista no que concerne ao número de manuscritos submetidos à avaliação nesse período e, destes, quantos foram aceitos e publicados. Em relação aos manuscritos náo aceitos para publicação, foram analisados os pareceres que fundamentaram a decisão editorial de recusa, buscando conhecer as justificativas apresentadas.

\subsection{AVALIAÇÁo dos MANUSCRITOS SUBMETIDOS}

A Tabela 1 apresenta o total de manuscritos recebidos para avaliação, independentemente da área de conhecimento, no período de 2007 a 2011, e o total de manuscritos da área de Educação Especial recebidos e recusados. 
Tabela 1 - Número total de manuscritos recebidos e não aceitos para publicação, e total de manuscritos da área de Educação Especial recebidos e não aceitos.

\begin{tabular}{ccccc}
\hline Ano & Recebidos & Recusados & $\begin{array}{c}\text { Educação Espe- } \\
\text { cial recebidos }\end{array}$ & $\begin{array}{c}\text { Educação Especial } \\
\text { não aceitos }\end{array}$ \\
\hline 2007 & 63 & 21 & 11 & 6 \\
2008 & 185 & 59 & 6 & 4 \\
2009 & 227 & 50 & 10 & 8 \\
2010 & 113 & 55 & 7 & 6 \\
2011 & 99 & 54 & 6 & 2 \\
\hline Total & 687 & 239 & 40 & 26 \\
\hline
\end{tabular}

Observando-se os dados da Tabela 1 constata-se que, dos 687 manuscritos submetidos à avaliação na revista, somente $7 \%$ tinham como foco de estudo a Educação Especial. Outro dado que chama a atenção é a diferença entre o percentual de manuscritos denegados no total e os manuscritos da Educação Especial. De fato, do total geral de manuscritos recebidos, foram denegados/recusados 239, ou seja, 34,7\% sendo que dos 40 manuscritos recebidos com temática voltada para a área de Educação Especial, 65\% não foram aceitos para publicação.

A Tabela 2 apresenta os dados relativos aos artigos de cada ano, considerando-se o número total de artigos nos três fascículos publicados por volume. Visando a classificar os artigos, tomando por base seu objeto de estudo, foram estabelecidas três categorias: 1) artigos em que o objeto de estudo é a Educação Especial, ou seja, estudos sobre a inclusão, programas de aprendizagem; 2) artigos em que o objeto de estudo é o deficiente - por exemplo, artigos que abordam a qualidade de vida do deficiente, seu desenvolvimento neuropsicomotor; e 3) as resenhas de livros da área de Educação Especial.

Tabela 2 - Total de artigos publicados por ano e número de artigos da área de Educação Especial publicados nos três fascículos editados por ano.

\begin{tabular}{ccccc}
\hline Ano & $\begin{array}{c}\text { No de artigos } \\
\text { por volume }\end{array}$ & $\begin{array}{c}\text { Educação } \\
\text { Especial }\end{array}$ & $\begin{array}{c}\text { Objeto de es- } \\
\text { tudo é a pessoa } \\
\text { com deficiência }\end{array}$ & $\begin{array}{c}\text { Resenhas/ } \\
\text { Educação } \\
\text { Especial }\end{array}$ \\
\hline 2007 & 31 & 2 & 2 & 1 \\
2008 & 36 & 1 & 0 & 0 \\
2009 & 39 & 0 & 2 & 0 \\
2010 & 36 & 0 & 1 & 0 \\
2011 & 39 & 1 & 3 & 1 \\
\hline Total & 181 & 4 & 8 & 2 \\
\hline
\end{tabular}

Ao se analisarem os artigos, considerando o objeto de estudo (Tabela 2), observase que dos 14 artigos publicados, somente quatro (28,5\%) tinham como foco a Educação Especial, enquanto que $57,1 \%$ tinha como foco a pessoa com deficiência, ou seja, são resultados de pesquisas que avaliam vários aspectos do deficiente como qualidade de vida, desempenho motor, nível intelectual e até mesmo a qualidade de vida de seus cuidadores.

Os dados apresentados nas Tabelas 1 e 2 mostram que os pesquisadores da área de Educação Especial têm se utilizado muito pouco da Paidéia para divulgarem os resultados 
de suas pesquisas. Pode-se supor que os pesquisadores desconhecem a linha editorial ou não reconhecem a Paidéia como um periódico relevante para a disseminação de conhecimento da área de Educação Especial, em que pese o fato de a revista ser avaliada com Qualis B1 na área de Educação.

\subsection{MOtIVOS DA RECUSA DE MANUSCRITOS SUBMETIDOS}

Baseando-se nos critérios estabelecidos pela revista para avaliação dos manuscritos, foi realizada análise de todos os pareceres emitidos no período de 2007 a 2011, visando a elencar os motivos mais frequentes para a recomendação de denegação. Os resultados dessa análise são descritos pormenorizadamente a seguir, buscando-se restringir as consideraçóes aos aspectos essenciais dos pareceres, de modo a preservar a confidencialidade do material analisado.

\subsection{Texto}

O manuscrito é avaliado pelos consultores ad hoc quanto à sua clareza, fundamentação teórica, e quanto à redação e organização do texto (ortografia, correção gramatical, clareza, objetividade, sequência lógica e coerência). Considerando esses requisitos, os pareceres dos manuscritos denegados apontam que o texto apresentado estava "confuso" em sua organização e sequência; era "superficial"; não deixava claro o contexto e/ou a fundamentação teórica da pesquisa. Esses problemas assinalados não se limitam ao conteúdo formal e à redação. Os pareceristas entenderam que são fragilidades que comprometem a consistência do trabalho submetido à avaliação.

\subsection{Objetivo}

Nesse requisito é avaliado se o objetivo do estudo está claramente definido e se é coerente com o título e com o problema investigado. Os pareceristas apontam que o objetivo, da maneira como foi redigido, "ficou muito amplo, vago" ou "não está claro". O problema de pesquisa e os objetivos estão mal formulados. Ou o autor buscou estabelecer relação discutível entre determinado aspecto que deseja analisar e a concepção de deficiência em questão.

\subsection{Método}

Avalia-se nesse tópico se a estratégia metodológica empregada está adequada aos objetivos do estudo, se o método está descrito adequadamente (sujeitos/participantes, procedimento de coleta e análise dos dados) e se a análise de dados está articulada aos objetivos e referencial teórico utilizado. Os assinalamentos contidos nos pareceres apontam aspectos críticos que remetem ao uso não apropriado do método. Entre outras questóes metodológicas foram assinaladas: o método escolhido não corresponde aos objetivos da pesquisa; o trabalho está fundamentado em bibliografia não atualizada, o que prejudica todo o desenvolvimento do manuscrito; o método está ancorado no paradigma compreensivo e, por essa razão, não viabiliza condições para avaliar, medir ou comparar, próprio do paradigma positivista e do método quantitativo; os autores não utilizaram instrumentos apropriados para avaliar o aprendizado dos alunos; não foi avaliada a eficácia do procedimento utilizado, entre outros apontamentos. 


\subsection{FUNDAMENTAÇÃo TEÓRICA, PERTINÊNCIA E ATUALIDADE DAS REFERÊNCIAS UTILIZADAS}

É avaliado nesse tópico se a revisão da literatura é pertinente e atualizada, adotandose como critério que pelo menos $50 \%$ das referências devem ter sido publicadas nos últimos cinco anos. Os pareceres mencionam pontos problemáticos, tais como: o manuscrito necessita de rigorosa revisão sobre o tema investigado; não são identificadas as lacunas do conhecimento da área; há autores citados no corpo do texto que não estão referenciados ao final; é insuficiente o número de referências bibliográficas que privilegiam artigos científicos publicados em periódicos indexados nacionais e internacionais nos últimos anos.

\subsection{CONCLUSÓES OU CONSIDERAÇÓES FINAIS}

São avaliados neste tópico se os principais resultados do estudo são ressaltados de forma clara e objetiva, se a discussão dos resultados é pertinente e suficiente, se o cotejamento entre os resultados da pesquisa, os dados e conceitos da literatura está bem articulado e se as conclusóes/consideraçóes finais são claras e baseadas nos achados do estudo. Alguns dos apontamentos assinalados são: o texto não apresenta uma conclusão (ou consideraçóes finais); os resultados não permitem que se cheguem às conclusôes apresentadas; o cotejamento entre os dados apresentados e o marco conceitual utilizado é superficial ou inconsistente.

Em síntese, a análise dos pareceres emitidos pelos consultores ad hoc da Paidéia mostra que a maioria dos manuscritos não foi aceita para publicação por falta de clareza no texto, descriçóes insuficientes do método empregado e conclusóes não fundamentadas nos resultados apresentados. É importante salientar que os manuscritos recusados quase sempre apresentavam mais de um critério avaliado como insuficiente, o que contribuiu para a decisão editorial de denegação.

Com base nos resultados apresentados, e apenas a título de ilustração, oferecemos a seguir um modelo de um parecer (fictício) enviado aos autores, contemplando de modo abrangente todos os problemas tipicamente assinalados pelos consultores ad hoc. Salientamos que esse "parecer" é totalmente fictício, tendo sido por nós montado com base na leitura dos diversos pareceres que recomendavam a não aprovação dos manuscritos.

\section{8PARECER FINAL}

Em que pesem a relevância da temática investigada e os esforços dos autores, o manuscrito apresenta sérios problemas que comprometem sua consistência científica. $\mathrm{O}$ problema da pesquisa está mal formulado e os objetivos não estão claramente definidos. Há falhas na descrição do método e na definição da fundamentação metodológica. Além disso, notam-se confusóes teórico-conceituais e equívocos no tratamento dos dados coletados, o que sugere que os autores desconhecem os procedimentos habituais de análise de dados provenientes de instrumentos de avaliação. Desse modo, o texto apresenta fragilidades metodológicas importantes, que comprometem os resultados apresentados, apesar da apresentação de alguns dados interessantes. Os achados são apresentados de maneira esquemática, sem que sejam estabelecidas relaçóes entre os dados obtidos. A discussão não abrange a complexidade dos 
dados, mantendo-se em um nível superficial. Pelo exposto recomendo que o manuscrito não seja aprovado para publicação.

\section{ConsideraçóEs FinAIS}

Considerando os dados apresentados, ressaltamos a importância de que os pesquisadores da área de Educação Especial reconheçam e utilizem os periódicos de outras áreas para divulgarem suas pesquisas, possibilitando assim maior visibilidade e disseminação dos conhecimentos científicos produzidos. O número de manuscritos de Educação Especial submetidos à Paidéia ainda é reduzido. Por outro lado, o percentual de recusa tem sido elevado quando comparado com o índice de recusa do total de manuscritos submetidos.

Uma vez que os dados mostraram que os motivos para o náo aceite de boa parte dos manuscritos não dizem respeito ao seu mérito, mas à falta de clareza e de informaçóes essenciais no texto, é necessário que os pesquisadores interessados em submeter seus estudos atentem para as normas de publicação do periódico, principalmente em relação à organização lógica, clareza e objetividade da redação.

\section{REFERÊNCIAS}

PAIDÉIA (RIBEIRÃO PRETO). Ribeirão Preto, n. 1, ago. 1991. Disponível em: <http://www. scielo.br/scielo.php?script=sci_arttext\&pid=S0103-863X1991000100001\&lng=pt\&nrm=iso $>$. Acesso em: 15 abr. 2013. http://dx.doi.org/10.1590/S0103-863X1991000100001.

SANTOS, M. A. Entre conquistas e perdas, nosso adeus à mestra. PAIDÉIA, Ribeirão Preto, v. 17, n. 36, 2007. Disponível em: http://www.scielo.br/scielo.php?script=sci_arttext\&pid=S0103-863X2 007000100001\&lng=pt\&nrm=iso $>$. Acesso em: 15 abr. 2013. http://dx.doi.org/10.1590/S0103863X2007000100001 